\title{
A Study On Effect Of Pharmacist Mediated Patient Counseling In Hypertensive Patients In Terms Of Knowledge, Compliance And Quality Of Life.
}

\author{
Chaudhary Gp ${ }^{1}$, M. Navyashree ${ }^{1}$, D. Sen Roy ${ }^{1}$, R.Srinivasan ${ }^{2}$ \\ Department of Pharmacy Practice, PES College of Pharmacy, Hanumanthnagar, Bangalore - 560 050, \\ Karnataka, India
}

\begin{abstract}
To create awareness about hypertension in order to improve their quality of life. Free health camps were conducted; screening of blood pressure was done. Data were collected based on medical history, family history, food and social habits and so on. Individual counselling was done in the respective languages in which they were comfortable. Feedback was collected from the patients regarding their satisfaction towards the camp and the services provided to them. Also, patient information leaflets containing the basic information about hypertension were provided to each patient to enhance their knowledge even further. There was a significant decrease in the blood pressure levels at the end of the study as compared to the beginning because they followed our advice and adhered to it, depicting that our counselling was beneficial in the improvement of their Quality Of Life. study conclude that providing individual counselling decrease in the blood pressure level
\end{abstract}

Keywords: Hypertension, Social Habits, Medical history, Counselling, Quality of life.

\section{Introduction}

Hypertension is a condition in which blood flows through the blood vessels with a force greater than normal, which is $120 / 80 \mathrm{mmHg}$. When the heart beats, it pushes blood through the arteries to the rest of the body. When the blood pushes harder against the walls of the arteries, the blood pressure goes up. This condition is commonly known as High Blood Pressure. Blood pressure may be different at different at different times of the day. It is usually higher as soon as we wake up, after exercise and under stress. Having higher blood pressure for short amounts of time is normal; however, if the blood pressure stays high for most of the time, it can cause serious health problems such as straining the heart, damage blood vessels, increase the risk of heart attack, stroke, kidney problems and death. Hypertension is the leading cause of mortality worldwide. It nearly affects about $26 \%$ of the population worldwide. It is predicted that by $2025,29 \%$ of the world's population will be affected with hypertension ${ }^{1}$. In 2000 , over 972 million adult populations were estimated to have hypertension ${ }^{1}$. Indian population accounts for 66 million hypertensive patients in which 34 million are from urban areas and 32 million are from rural areas. In India, prevalence of hypertension is increasing rapidly, 25\% in urban areas and $10 \%$ in rural areas. Uncontrolled blood pressure accounts for 7.1 million deaths worldwide each year as it doubles the risk of cardiovascular diseases including stroke, congestive heart failure, coronary heart disease and renal failure. Repeated measures of blood pressure will determine whether initial elevations persist and require immediate attention or return to normal values and require only surveillance. The 140/90 $\mathrm{mmHg}$ cut point correlates to acceleration in $\mathrm{CV}$ risk that has been established from natural history studies (The Framingham Heart Study). Classification of Blood Pressure for Adults Aged 18 Years and Older ${ }^{1}$ :-

1. Normal

2. Pre-Hypertension

3. Hypertension

4. Stage I

5. Stage II
$<120$ ( Systolic $\mathrm{mm} \mathrm{Hg}$ ) and $<80$ (Diastolic $\mathrm{mmHg}$ )

120-139 (Systolic $\mathrm{mm} \mathrm{Hg}$ ) and 80-89 (Diastolic $\mathrm{mmHg}$ )

>_ 140 (Systolic $\mathrm{mm} \mathrm{Hg}$ ) and >_90 (Diastolic $\mathrm{mmHg}$ )

140-159 (Systolic $\mathrm{mm} \mathrm{Hg}$ ) and 90-99 (Diastolic $\mathrm{mmHg}$ )

>_ 160 (Systolic mm Hg) and >_100 (Diastolic mmHg)

II. Methodology

Table-1: list of instruments used

\begin{tabular}{|c|l|l|}
\hline Sl.no & Instruments & Manufacturer \\
\hline 1. & Automatic blood pressure screening machines & OMRON \\
\hline 2. & Digital Weighing machine & SAMSO \\
\hline
\end{tabular}

Table-2: list of materials used

\begin{tabular}{|l|l|}
\hline Sl.no. & Materials \\
\hline 1 & Registrations forms \\
\hline 2 & Patient ID cards \\
\hline 3. & Data collection forms \\
\hline
\end{tabular}




\begin{tabular}{|l|l|}
\hline & \\
\hline 4. & BP awareness pamphlets \\
\hline 5. & Feedback forms \\
\hline 6. & Pamphlets \\
\hline 7. & Badges (“we care for you") \\
\hline 8. & Volunteer T-shirts("Be Healthy be Happy") \\
\hline
\end{tabular}

\subsection{Advertisement of the camp:}

More than 300 pamphlets were designed which included the details of the camp- date, timings, venue and the services to be provided to the patients. First pamphlets were issued to all the volunteers and were distributed in area such as Hanumanthnagar, Girinagar, Srinivasanagar, Bank colony, Srinagar and other areas which are at a distance of 4-5 kilometers radius from PES college Of Pharmacy which mainly included parks, pharmacies, bus stops and other places where the crowd was huge. Apart from the distribution of pamphlets social networks such as (Facebook, What Sapp, etc) were used as communication media with an objective to create awareness regarding the free health camp. Free health camp flex banners were designed and arranged at different places to attract more no. of patients towards the study. All these activities were performed three days prior to conduction of health camps.

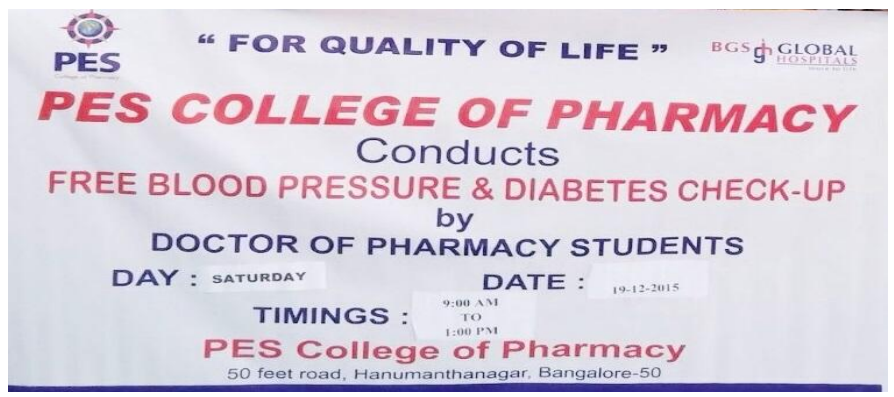

Fig 1:- banner used for the camp

\subsection{Setting up of the venue:}

The venue was set up with the help of the volunteers. Chairs were arranged for the comfort of the patients so that they don't have to stand while waiting for their turn to get their blood pressure checked. Counters were arranged accordingly and placards were placed on each counter for BP measurement, data collection, patient counseling, collection of feedback and patient information leaflet distribution respectively. Also, purified water cans were placed at the entrance, for the comfort of the patients and volunteers. Each counter had a minimum of two trained volunteers to guide the patients further.

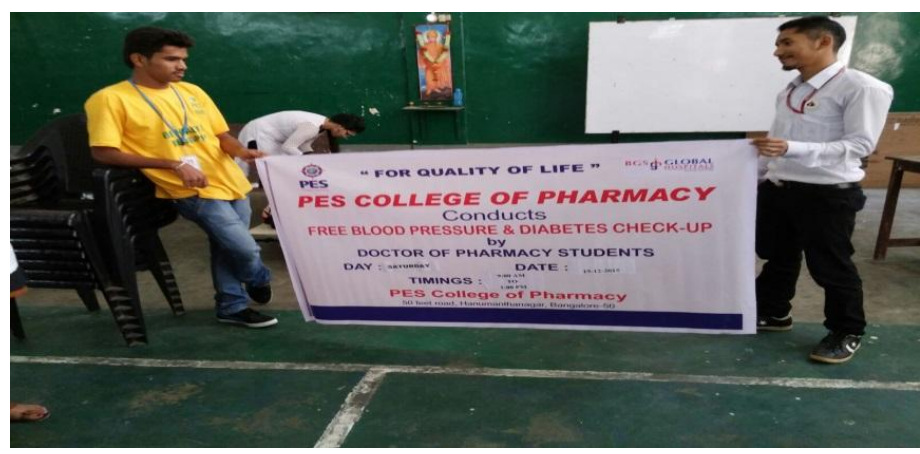

\subsection{Inclusion criteria:}

Fig 2:- setting up of the venue

Patients diagnosed with hypertension of either gender, Patients under the age group of 20-85 years, Patients who are willing to participate in the study, Patients with or without co morbid conditions.

\subsection{Exclusion criteria:}

Pregnant women and lactating mothers, Paediatric population, Psychiatric patients, Patients with severe chronic illness and patients admitted in ICU, Patients who are not willing to participate.

\subsection{Patient's registration:}

On the day of the camp, the patients were made to register at the registration desk placed just at the entrance of the venue where the name, age, sex and weight of the patients were recorded by the volunteers in the Identity Cards provided to each of them, and were further guided to sit on the chairs provided, for few minutes in order to get their heart rate to the normal pace. 


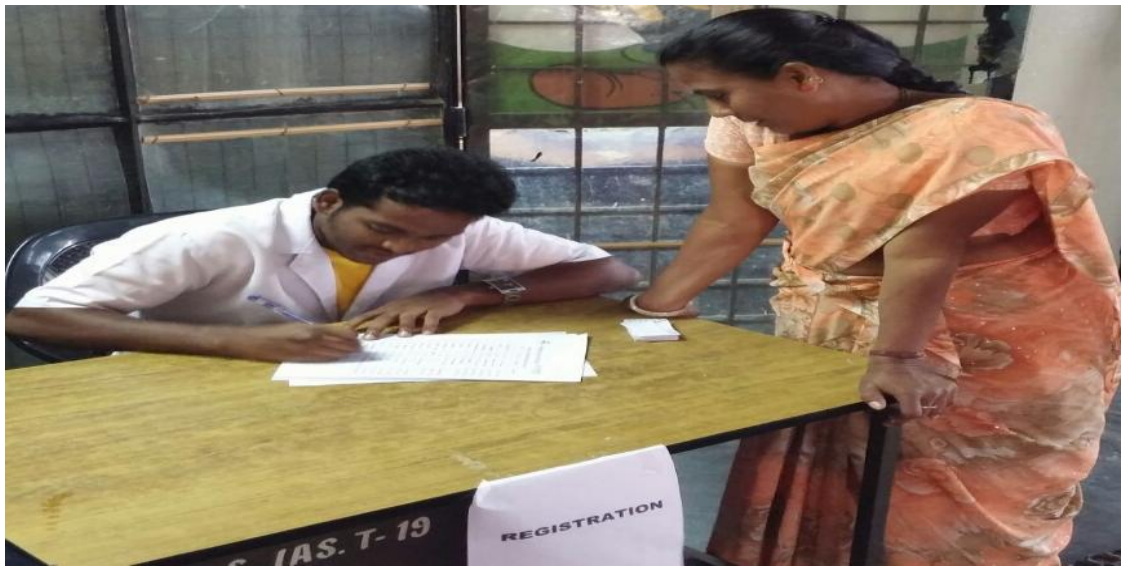

Fig 3:- registration counters where the patients were weighed and their name \& contact details were collected.

\subsection{Patient's blood pressure screening:}

After the rest of 4-5mins, the patients were sent to the BP screening desk for the screening of the blood pressure using the advanced digital Sphygmomanometers and Automatic blood pressure screening machines. The values of their blood pressure and pulse were recorded in the patient ids provided to each of them.

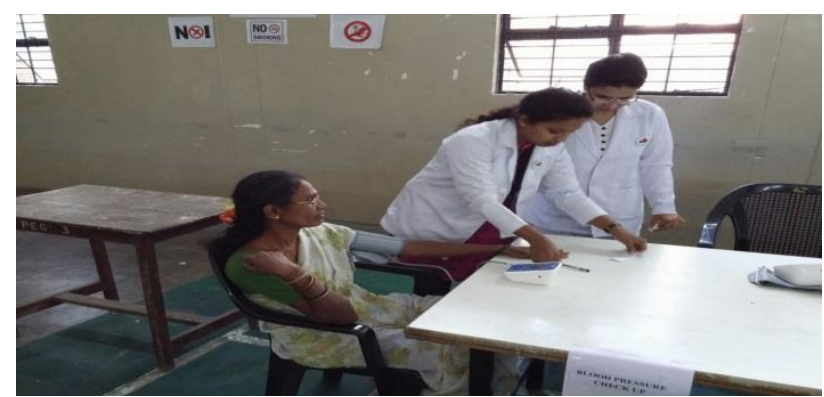

Fig 4:- measurement of blood pressure and pulse rate

\subsection{Data collection:}

After their screening was done they were guided to the next desk by our volunteers for the data collection. The data collection forms consist the details regarding their existence of any co-morbid conditions, past medical histories, past medication histories, their family histories and also any other unusual symptoms they experience in their day to day routine.

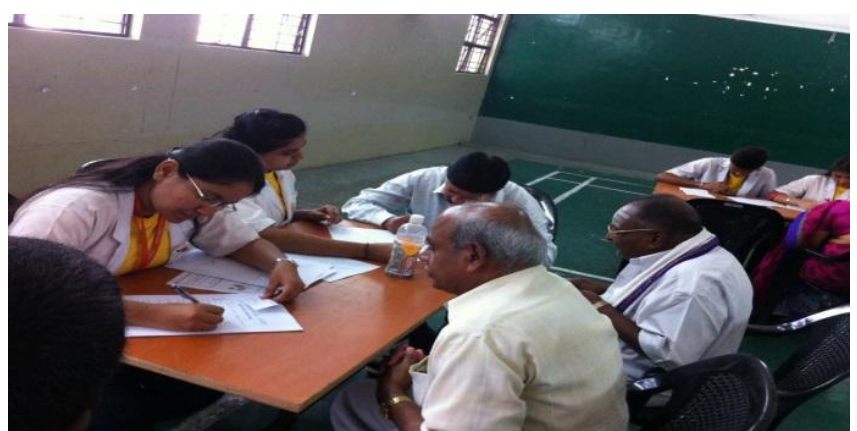

Fig 5:- data collection counter

\subsection{Patient counseling:}

After their data collection, they were guided to the patient counseling desk where our volunteers (trained by us), counseled the patients. Patient counseling was provided individually to every patient in different languages such as English, Hindi, Kannada and Telugu languages according to the comfort of the patient. The patients were educated regarding High blood pressure, the basic and important facts they need to know about high blood pressure, Factors causing the high blood pressure and the normal blood pressure. Also, patients were counseled about different topics that lead to high blood pressure such as Adherence towards the medications, Dietary advice, Lifestyle modification including exercises, Social habits causing high BP 


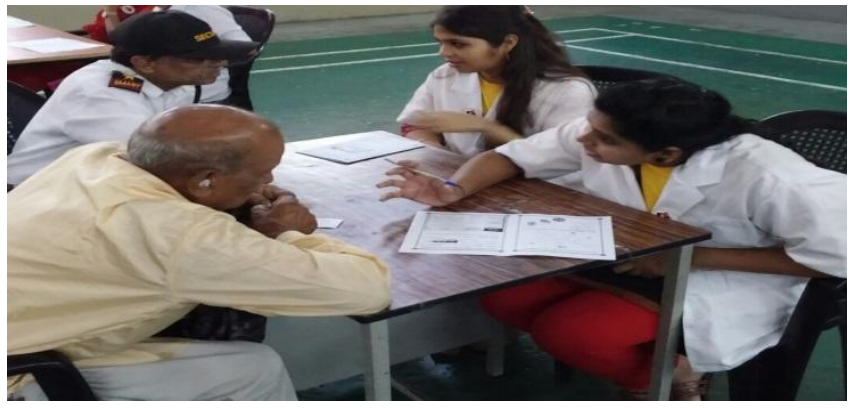

Fig 6:- patient counseling counter

Individual patient counseling was given to all the patients based on their health condition, smoking and drinking habits, food habits (vegetarian or non-vegetarian) and exercise schedule to understand and take care of their health in a better way. Also, the patients' doubts regarding the same were clarified by our trained volunteers in their respective languages. For the convenience of the patients, brochures were designed containing the basic and necessary details about Hypertension, dietary advice and lifestyle modification. Also, pictures were added to further simplify the details to the patients.

\subsection{Feedback collection:}

The patients were further guided towards the feedback desk in order to receive their feedback regarding Weather the camp was beneficial to them or not, Their satisfaction with the health screening done on them, Their satisfaction with the counselling provided to them, The counselling provided regarding their medication, diet and lifestyle modification, Their interest in participating in the further camps, And finally, their suggestions by which we can make the camp better. The main objective of designing the feedback forms was to provide more benefit and convenience to the patients.

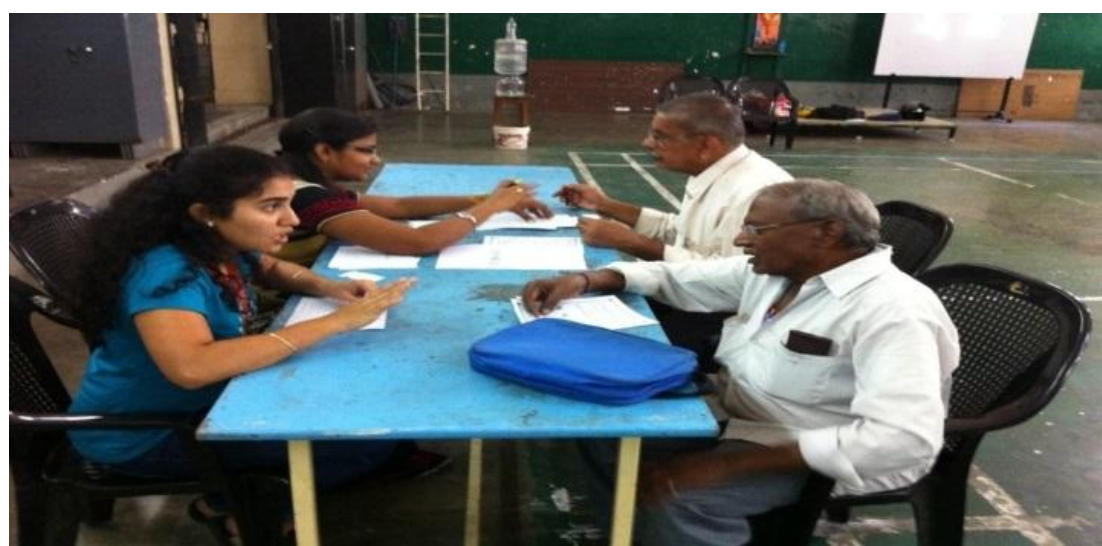

Fig 7:- feedback collection

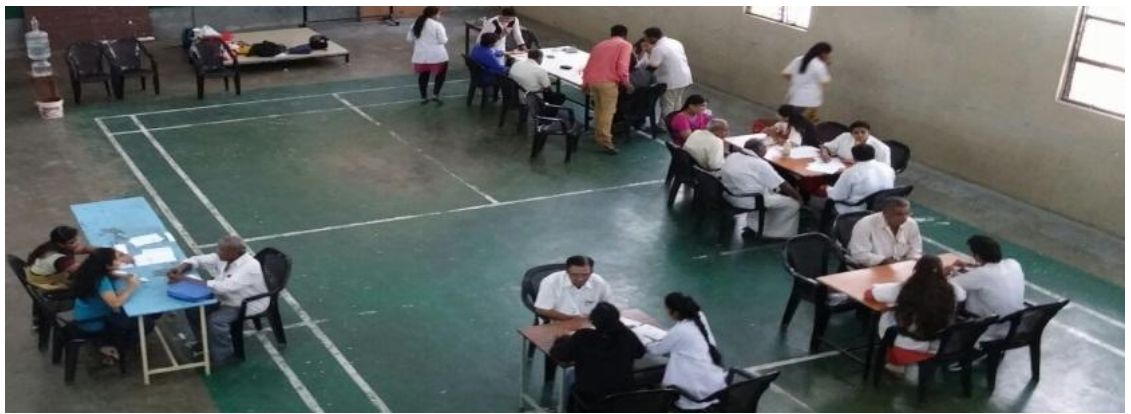

Fig 8:- overview of the camp

\subsection{Follow-up:}

Consecutive follow-ups were done on the patients periodically to monitor their blood pressures and to observe any elevation in the blood pressure or any other unusual symptoms. In case Patients fails to attend the camps, follow up were done via telephone and home visit. The volunteers of the day of the camp were provided with yellow colour T-shirts with theme of "BE HEALTHY AND BE HAPPY" 


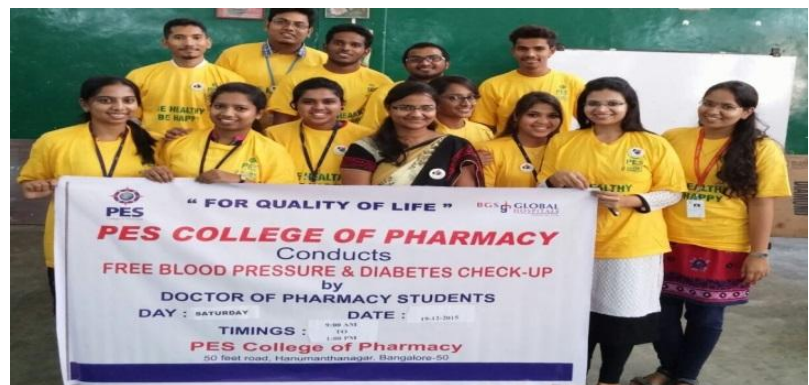

Fig 9:- volunteers of the health camp

At each desk a minimum of 2 -3 volunteers and were assigned to guide the patients, for their convenience. Badges "WE CARE FOR YOU" were designed and provided to all the volunteers, with objectives to provide positivity about quality of life to the patients.

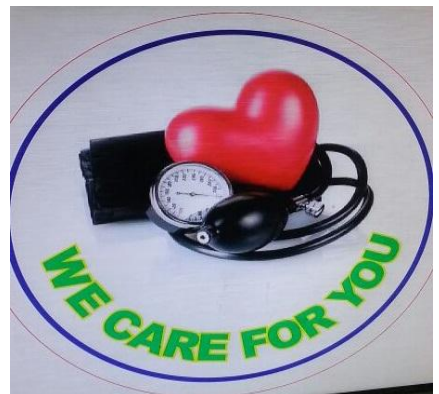

Fig 10:- Badges designed for volunteer

\section{Results}

Table-3: Age Distribution Of Study Population

\begin{tabular}{llll} 
& Total no. of patients & Males & Females \\
\hline $20-30$ yrs & 4 & 4 & 0 \\
\hline $31-40$ yrs & 15 & 7 & 8 \\
\hline $41-50$ yrs & 28 & 16 & 12 \\
\hline $51-60$ yrs & 20 & 15 & 5 \\
\hline $61-70$ yrs & 30 & 27 & 3 \\
\hline $71-80$ yrs & 9 & 9 & 0 \\
\hline $81-90$ yrs & 1 & 1 & 0 \\
\hline & Total= 107 & 79 & 28 \\
\hline
\end{tabular}

We observed that that among 107 patients who were included in the study, majority (30) of the patients belonged to the age group of 61-70 years in which 27 were males and 3 were females (Table-5) which shows that age is a major factor affecting the condition due to altered physiology and co-morbid conditions.

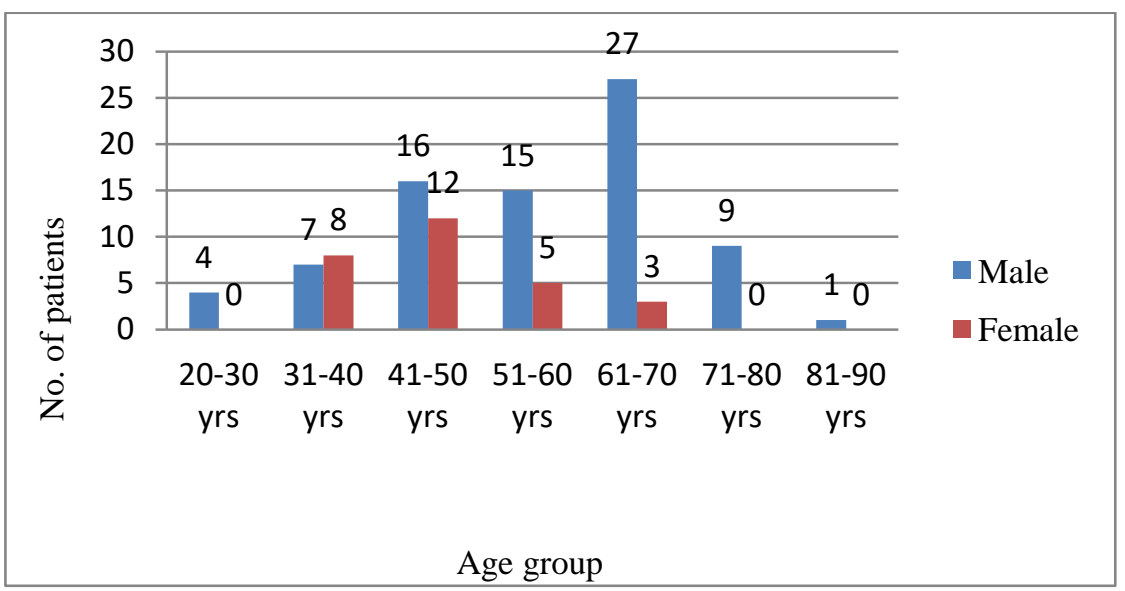

Fig 11:- Age distribution of patients 
Table-4: Gender Distribution of Study Population

\begin{tabular}{|l|l|l|}
\hline Gender & No. of patients & \% of patients \\
\hline Male & 79 & 74 \\
\hline Female & 28 & 26 \\
\hline
\end{tabular}

Considering the gender wise distribution, we observed maximum $79(73.83 \%)$ were males and $28(26.16 \%)$ were females (Table-6) because of the social habits of males such as smoking and alcohol.

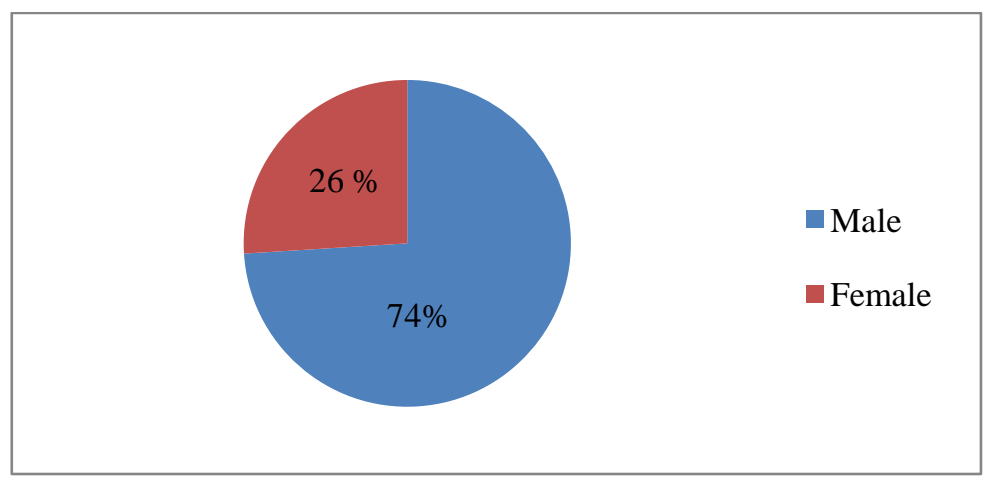

Fig 12:- Gender distribution of the patients

Table- 5: Family History of Study Population

\begin{tabular}{|l|l|l|}
\hline Family History & No. of Patients & $\%$ of Patients \\
\hline Present & 22 & $20 \%$ \\
\hline Absent & 37 & $35 \%$ \\
\hline Unknown & 48 & $45 \%$ \\
\hline
\end{tabular}

Regarding the family history of the study population $20.56 \%$ of the patients had the family history of hypertension, $34.57 \%$ of the patients did not have any family history of Hypertension, $44.85 \%$ of the patients did not know about their family history of Hypertension (Table-7). Due to this they were not aware of the possibility of occurrence and did not take necessary precautions.

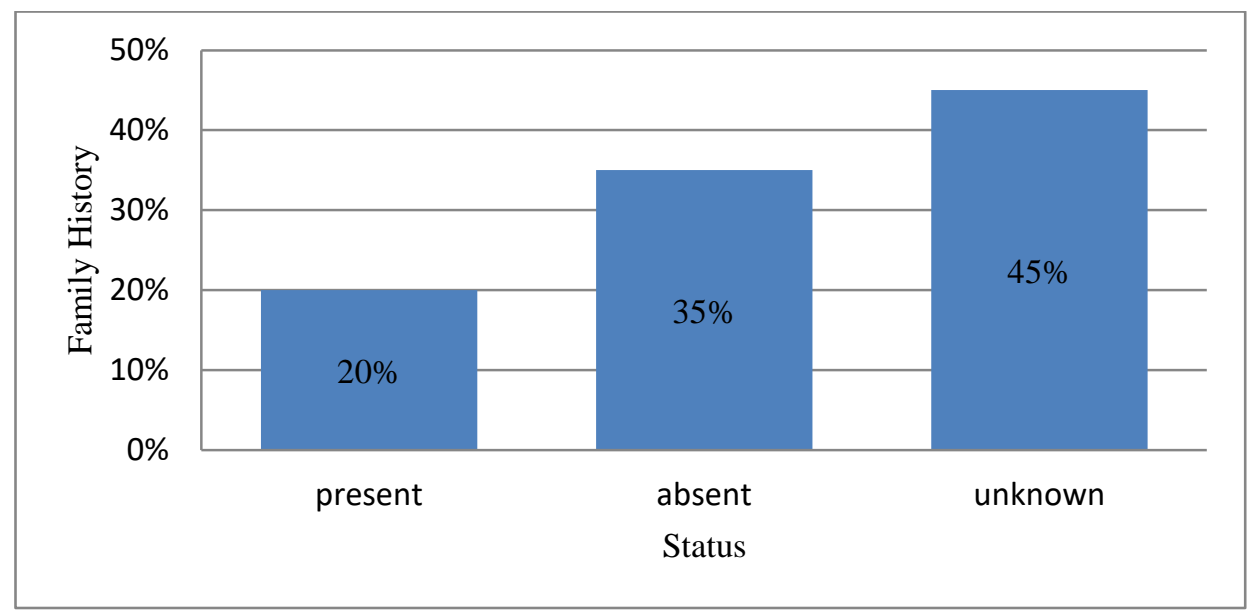

Fig 13:- Family history of study population

Table-6: Distribution of Study Population By Social Habits

\begin{tabular}{|l|l|l|}
\hline Smoking/Alcohol & No. of Patients & $\%$ of Patients \\
\hline Present & 37 & $35 \%$ \\
\hline Absent & 70 & $65 \%$ \\
\hline
\end{tabular}

Considering the social habits of the study population, $34.57 \%$ of the study population have the habit(s) of smoking and alcohol consumption, $65.42 \%$ of the study population do not have any habits of smoking and alcohol consumption (Table-8) which are major risk factors of hypertension. 


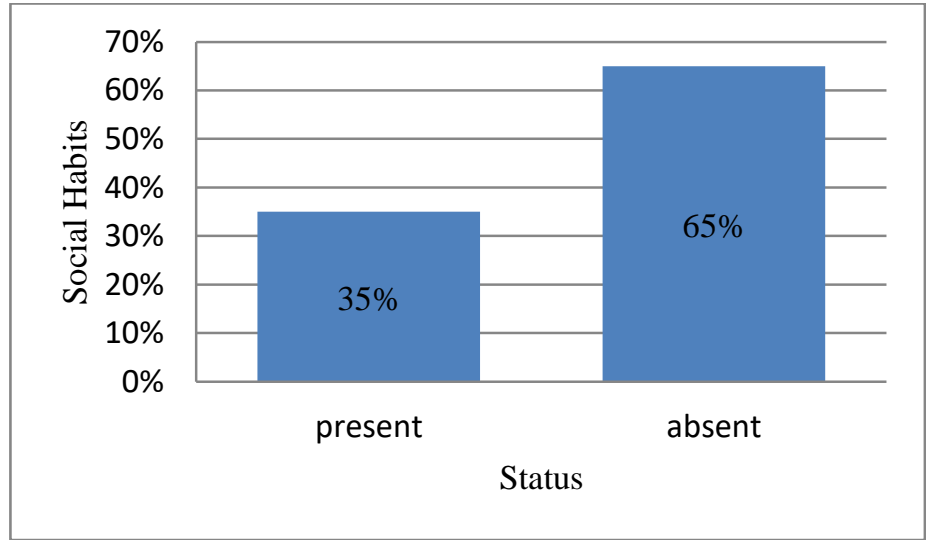

Fig 14:- Distribution of study population by social habits

Table-7: Distribution of Study Population By Food Habits

\begin{tabular}{|l|l|l|}
\hline Diet & No. of Patients & $\%$ of Patients \\
\hline Vegetarian & 27 & $25 \%$ \\
\hline Non-Vegetarian & 80 & $75 \%$ \\
\hline
\end{tabular}

Dietary habits were considered, amongst which $25.23 \%$ of the study population follow a vegetarian diet, $74.76 \%$ of the study population follow a non- vegetarian diet (Table-9) depicting that blood pressure levels are high in people who consume non-vegetarian food which is also a risk factor.

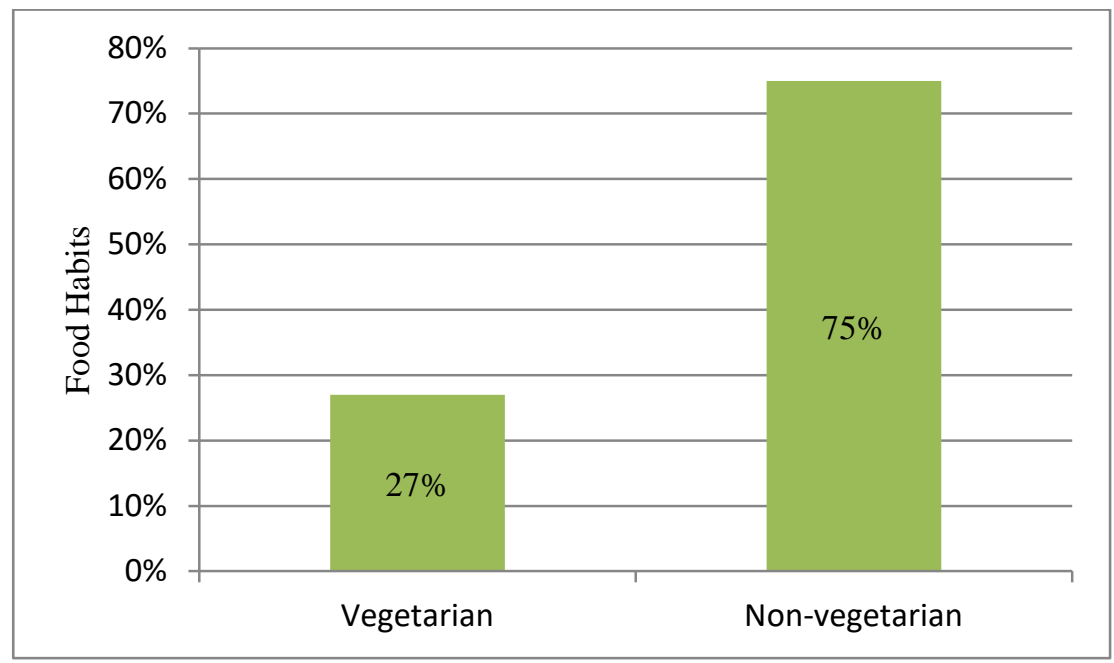

Fig 15:- Distribution of study population by diet

Table-8: Distribution of Study Population By Knowledge, Compliance And Lifestyle Modification Before And After Counseling

\begin{tabular}{|l|l|l|l|l|l|}
\hline Sl. No. & Description & \multicolumn{2}{l|}{$\begin{array}{l}\text { Before } \\
\text { counseling }\end{array}$} & \multicolumn{2}{l|}{$\begin{array}{l}\text { After } \\
\text { Counseling }\end{array}$} \\
\hline 1. & Do you know about Hypertension? & 55 & $51 \%$ & 95 & $89 \%$ \\
\hline 2. & $\begin{array}{l}\text { Do you know about the signs and symptoms } \\
\text { of Hypertension? }\end{array}$ & 33 & $31 \%$ & 85 & $79 \%$ \\
\hline 3. & Do you know how to control Hypertension? & 27 & $25 \%$ & 102 & $95 \%$ \\
\hline 4. & Do you know your blood pressure? & 25 & $23 \%$ & 75 & $70 \%$ \\
\hline 5. & Do you exercise regularly? & 42 & $39 \%$ & 98 & $92 \%$ \\
\hline 6. & Do you know which diet has to be followed? & 47 & $44 \%$ & 85 & $79 \%$ \\
\hline 7. & Are you adherent towards your medications? & 80 & $75 \%$ & 103 & $96 \%$ \\
\hline
\end{tabular}

Table-9 shows the improvement in the study population in terms of knowledge, compliance and lifestyle modification after the individual counseling was provided to them. 


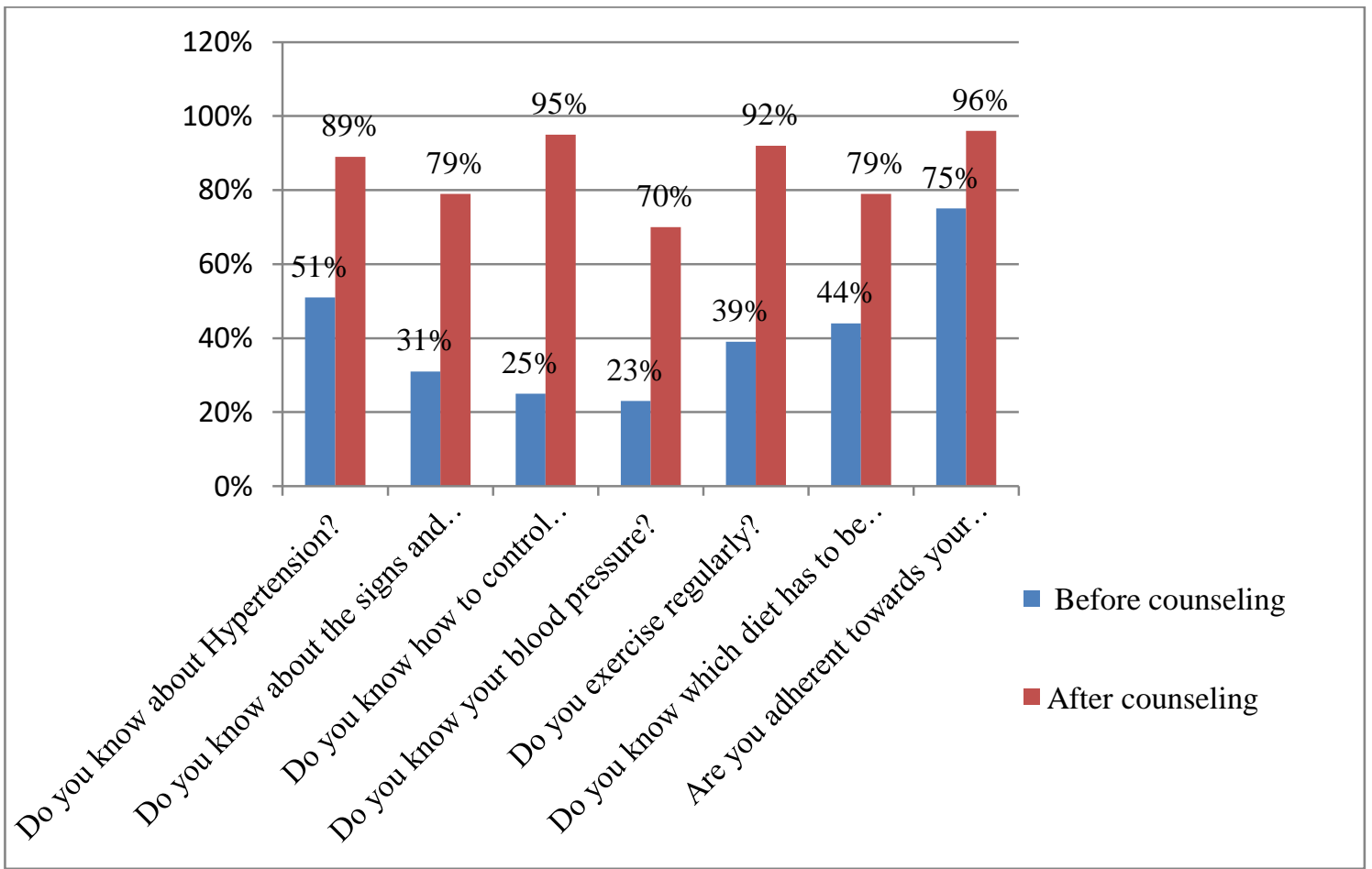

Fig 16:- Distribution of study population by knowledge, compliance and lifestyle modification before and after counseling.

Table-9: Outcome of the Study

\begin{tabular}{|l|l|}
\hline Blood pressure & Decrease in $\mathrm{mm} / \mathrm{Hg}$ \\
\hline Systolic & $20 \mathrm{~mm} / \mathrm{Hg}$ \\
\hline Diastolic & $10 \mathrm{~mm} / \mathrm{Hg}$ \\
\hline
\end{tabular}

Average decrease in systolic blood pressure $=20 \mathrm{~mm} / \mathrm{Hg}$

Average decrease in diastolic blood pressure $=10 \mathrm{~mm} / \mathrm{Hg}$

Table-9 shows that there was a significant decrease in the blood pressure levels at the end of the study as compared to the beginning because they followed our advice and adhered to it, depicting that our counseling was beneficial in the improvement of their Quality Of Life.

\section{Conclusion}

After we provided individual counselling to the patients, we interpreted that there was a significant decrease in their blood pressure levels, their knowledge about signs and symptoms, management of hypertension was increased. Also they were more adherent to the medications, exercised more often, reduced the frequency of smoking \& alcohol consumption and followed a proper healthy diet as advised by us. This lead to an improvement in their blood pressure and overall health status. From our study we concluded that Pharmacist mediated patient counselling is very essential and plays a vital role in improving the Health Related Quality of Life in hypertensive patients as there was a significant decrease in their blood pressure at the end of the study.Thus, it is very important to create awareness about hypertension and this can be done by conducting free health camps providing information leaflets and individual counselling in their own language using layman terms and this helps in effective communication between the pharmacist and patients.

\section{Bibliography}

[1]. Williams Lippincott, Wilkins, practical cardiology evalution and treatment of common cardiovascular disorders, 2008:219-227

[2]. Pawar S, Lokhande KD, Padma S, Diwan A. Effect of pharmacist mediated patient counseling in hypertensive patients in terms of knowledge , compliance and lifestyle modification. Int J Pharm Pharm Sci. 2014;6(4):277-2781.

[3]. Biradar SS, Reddy S, Raju SA, Kapatae R. Assessment of pharmacist mediated patient counseling on knowledge, attitude and practices on hypertension in compliance with antihypertensive drugs in south Indian city. Int J Pharm life Sci. 2012;3(6):17331738.

[4]. Biradar S., Rajashekhar K, Srinivas R, S A R. Role of pharmacist towards knowledge attitude and practice in compliance with hypertension in north karanataka in south indian. Int Res J Pharm. 2012;3(5):17-20.

[5]. Biradar SS, Rajashekhar K, Srinivas R, Raju SA. Assesment of pharmacist mediated patient counseling on hypertension incompliance with quality of life in south indian city. 2012;3(1):206-209. 
[6]. Biradar SS, Kapatae R, Reddy S, Raju SA, College H, Karnataka G. Importance of role of pharmacist mediated adherence in hypertensive patients a brief overview. Int J Res Dev Pharm Life Sci. 2012;1(1):11-15.

[7]. Manandhar K, Koju R, Np S, Humagain S. Prevalence and associated risk factors of hypertension among people aged 50 years and more in banepa. 2012;10(3):35-38.

[8]. Shankar S, Kumar U, Kini S, Kumar A. Knowledge, attitude and practice of hypertension among adult hypertensive patients at a rural clinic of coastal Karnataka. IOSR J Dent Med Sci. 2014;13(12):33-35.

[9]. Sharma Sushmita*,Khanal Aarati, Poudel Bharat, Sharma Roshani,Srivastav Sunil, Parajuli Kalpana UDKS. Knowledge , attitude and practice outcomes : an effect of pharmacist provided counseling in hypertensive patients in a tertiary care teaching hospital in western nepal. Int J Pharm Sci. 2010;2(2):583-587.

[10]. Association, Canadian Pharmacists, C.Davies, Y.li PE. Pharmacists' role in hypertension management. www.pharmacists.ca/research. 2014;8(1):8-11.

[11]. Bugdalski-stutrud C, Moser LR. Hypertension outcomes of a pharmacist-provided hypertension Service. Pract Based Res. 2014;4(3):1-9.

[12]. Association OP, Canada GS. Impact of community pharmacist interventions in hypertension management on patient outcomes

[13]. Alsaikhan F, Abd-elaziz MA, Alsubaie M, Aldosari SA. Antihypertensive medications and chronopharmacology: role of saudi pharmacists in patient education. Int J Dev Res. 2015;5:3831-3835.

[14]. Chiazor ei, evans $\mathrm{m}$, woerden $\mathrm{h}$ van, oparah ac. A systematic review of community pharmacists ' interventions in reducing major risk factors for cardiovascular disease. Elsevier. 2015;9-21.

[15]. Sekokotla D, Bradshaw D. Hypertension management and surveillance at primary care level : a situational analysis in. 2003.

[16]. Morishita R. World Journal of Hypertension. World J Hypertens. 2011;1(1). 